\title{
The Shikotan earthquake of October 4, 1994: Lithospheric earthquake
}

\author{
Masayuki Kikuchi \\ Department of Physics, Yokohama City University, Yokohama, Japan
}

\section{Hiroo Kanamori}

Seismological Laboratory, California Institute of Technology, Pasadena

\begin{abstract}
A large $M_{w}=8.2$ earthquake occurred off Shikotan Is., one of the Kurile Is., on October 4,1994 . We inverted 32 body-wave records to determine the rupture pattern using an iterative deconvolution method. The mechanisms of the subevents were allowed to vary during rupture. The source parameters obtained are: the location of the initial break $=\left(43.48^{\circ} \mathrm{N}, 147.40^{\circ} \mathrm{E}\right)$; the centroid depth $=56 \mathrm{~km}$; (strike, dip, rake) $=\left(49^{\circ}, 75^{\circ}\right.$, $\left.125^{\circ}\right)$ for the total source; the seismic moment $M_{o}=$ $2.6 \times 10^{21} \mathrm{Nm}\left(M_{w}=8.2\right)$; source time duration $T=42 \mathrm{~s}$; the average rupture velocity $v=2.5 \mathrm{~km} / \mathrm{s}$. We also determined the mechanism using long-period Love and Rayleigh waves from 14 stations. The solution for a finite source distributed over a depth range from 0 to 90 $\mathrm{km}$ is (strike, dip, rake) $=\left(54^{\circ}, 76^{\circ}, 129^{\circ}\right)$ with $M_{0}=$ $2.3 \times 10^{21} \mathrm{Nm}$, in good agreement with that from body waves. Referring to the extent of the aftershock area and the subevent distribution, we estimated the fault area $S=120 \times 60 \mathrm{~km}^{2}$, the average slip $D=5.6 \mathrm{~m}$, and the stress drop $\Delta \sigma=11 \mathrm{MPa}$. We computed synthetic waveforms as well as static displacements using either the steep or the low-angle plane as the fault plane, and found that the steep-dip fault model fits the data better. Our result (the mechanism, large centroid depth, high stress drop) strongly suggests that the 1994 Shikotan earthquake is a lithospheric earthquake: an intra-plate event that ruptures through a substantial part of the subducting oceanic lithosphere. This type of lithospheric earthquake is relatively common.
\end{abstract}

\section{Introduction}

A large earthquake occurred off Shikotan Is., one of the Kurile Is., on October 4, 1994 (Figure 1(a)). We call this earthquake the Shikotan earthquake in this paper. It is also called the Hokkaido-Toho-Oki earthquake by the Japan Meteorological Agency (JMA). The hypocentral parameters given by the National Earthquake Information Service (NEIS) are: origin time $=13: 22: 58.1 \mathrm{UT}$, epicenter $=\left(43.668^{\circ} \mathrm{N}\right.$, $\left.147.336^{\circ} \mathrm{E}\right)$, depth $=33 \mathrm{~km}$, magnitude $=8.1\left(M_{s}\right)$, and those by JMA are: origin time $=13: 22: 57.2$ UT, epicenter $=$ $\left(43.37^{\circ} \mathrm{E}, 147.66^{\circ} \mathrm{E}\right)$, depth $=30 \mathrm{~km}$, magnitude $=8.1$.

The location and the magnitude of this earthquake are very similar to those of the 1969 Kurile Is. earthquake $\left(43.44^{\circ} \mathrm{N}\right.$, $147.82^{\circ} \mathrm{E}, M_{w}=8.2$ ) as shown in Figure 1(a). Since most

Copyright 1995 by the American Geophysical Union.

Paper number 95GL00883

0094-8534/95/95GL-00883\$03.00 large earthquakes in subduction zones are thrust earthquakes on the subduction plate interface, and the repeat time of such. earthquakes along the Kurile Is. is believed to be about 100 years [see Utsu, 1972; Kanamori, 1977; Shimazaki, 1978], the occurrence of this earthquake only 25 years after the 1969 earthquake was initially considered somewhat unusual. However, examinations of long-period surface waves and body waves soon revealed that the 1994 earthquake is not a thrust earthquake on the plate interface.

\section{Mechanism}

We retrieved the broadband seismograms recorded by IRIS network and chose the stations at distances between $30^{\circ}$ and $100^{\circ}$ as shown in Figure 1(b). The azimuthal coverage is good except in the western azimuth. The records were converted into ground motion displacement and bandpassed between $2 \mathrm{mHz}$ and $1 \mathrm{~Hz}$. We inverted 32 body-wave records (vertical $P$ - and $\mathrm{SH}$-components) to determine a sequence of subevents using the iterative deconvolution method of Kikuchi and Kanamori [1991].

We allowed the mechanism to change during rupture. In synthesizing waveforms, we used a three-layer structure with a $2 \mathrm{~km}$ thick water layer and a $20 \mathrm{~km}$ thick crust ( $P$-wave velocity, $\alpha=6.50 \mathrm{~km} / \mathrm{s}, S$-wave velocity, $\beta=3.74 \mathrm{~km} / \mathrm{s}$, density, $\left.\rho=2.87 \times 10^{3} \mathrm{~kg} / \mathrm{m}^{3}\right)$ overlying a semi-infinite mantle $(\alpha=7.80$ $\mathrm{km} / \mathrm{s}, \beta=4.40 \mathrm{~km} / \mathrm{s}, \rho=3.30 \times 10^{3} \mathrm{~kg} / \mathrm{m}^{3}$ ) for the source region, and the standard Jeffreys-Bullen model for receiver sites. We first fixed the source time function and varied the depth. The best waveform match was obtained for a depth of $50 \mathrm{~km}$. Considering the uncertainty in the model structures, we estimate that the probable centroid depth is from 40 to $60 \mathrm{~km}$.

In the inversion above, the start times of the records were first determined using the Jeffreys-Bullen table and the NEIS hypocenter. Then by matching the waveforms we determined the time corrections for each station, which in turn were used to relocate the initial break of the main shock. This location is at $43.48^{\circ} \mathrm{N}$ and $147.40^{\circ} \mathrm{E}$. We obtained two subevents with this inversion. The two subevents have nearly identical reversefault mechanisms with a considerable strike-slip component: $\left(\operatorname{strike}\left(\phi_{s}\right), \operatorname{dip}(\delta), \operatorname{rake}(\lambda)\right)=\left(56^{\circ}, 71^{\circ}, 125^{\circ}\right) /\left(44^{\circ}, 79^{\circ}, 129^{\circ}\right)$ for 1st / 2nd subevents.

We also determined the mechanism using long-period Love and Rayleigh waves from 14 stations using the method of Kanamori and Given [1981]. The solution is $\left(\phi_{s}, \delta, \lambda\right)=\left(54^{\circ}\right.$, $76^{\circ}, 129^{\circ}$ ) and in good agreement with that from body waves. These solutions are similar to the Harvard CMT solution $\left(51^{\circ}\right.$, $\left.76^{\circ}, 125^{\circ}\right)$ and the NEIS solution: $\left(55^{\circ}, 81^{\circ}, 140^{\circ}\right)$. The $P$ wave first motion solution determined by JMA is $\left(74^{\circ}, 77^{\circ}\right.$, $140^{\circ}$ ). 

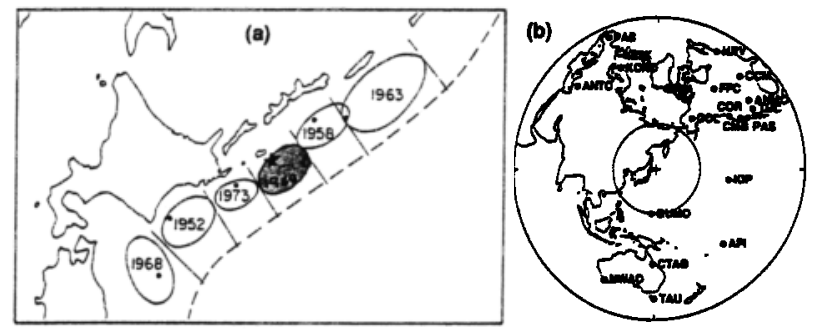

Figure 1. (a) Aftershock areas of previous large earthquakes in the Kurile Islands region. The epicenter of the 1994 Shikotan event is denoted by a star symbol. The base figure is taken from figure 12 of Fukao and Furumoto (1979). (b) IRIS broadband seismograph stations. Small and large circles indicate the epicentral distances of $30^{\circ}$ and $100^{\circ}$, repectively.

\section{Fault-Plane}

Usually one of the two $P$-wave nodal planes can be identified as the fault plane using the geometry of the aftershock distribution. Figure 2 shows the distribution of the aftershocks one day after the mainshock determined by the Research Center of Earthquake Prediction, Hokkaido University [Katsumata et al., 1995]. The main shock epicenter shown in this figure is that relocated with body wave inversion. The aftershock area extends southwest from the mainshock epicenter, suggesting unilateral rupture propagation to southwest. The length of the aftershock area is about $120 \mathrm{~km}$.

The cross sections of the aftershock distribution shown in Figure 2 seem to favor the steep nodal plane as the fault plane, as indicated by a shaded zone in the cross section perpendicular to $\mathrm{N} 60^{\circ} \mathrm{E}$. However, from the aftershock distribution alone, the possibility that the shallow-dip nodal plane with SE-NW strike is the fault plane cannot be ruled out.

To determine which of the nodal planes is the fault plane we inverted the waveforms assuming each of the nodal planes as the fault plane. With the assumption that rupture propagates almost unilaterally at a constant speed, we used triangular source time functions and determined the space-time distribution of point sources with the least-squares method. The steep-fault model resulted in better waveform match than the shallow-dip fault model. To explain the initial part of the waveforms we found it necessary to keep the energy release at a relatively large depth during the entire rupture propagation. For the steep-fault model, the energy release could be confined at a relatively large depth, and the waveforms could be explained better. In contrast, for the shallow-dip fault model, the rupture must start in the shallowest point and propagate southwest down-dip, since the initial break is located near the northeastern end of the aftershock area.

\section{Source Parameters}

The results for the steep-fault model are shown in Figures 3(a) and 3(b). The fault mechanism changed very little during rupture. The rupture propagated to the southwest over a distance of about $100 \mathrm{~km}$ and to the northeast over a distance of about $20 \mathrm{~km}$. Point dislocations with mechanism 1 occupy three grid points at the same depth, $h=50 \mathrm{~km}$, while those with mechanism 2 occupy three grid points at each depth of $h$ $=50 \mathrm{~km}$ and $70 \mathrm{~km}$. This suggests that the later subevents ruptured slightly deeper portions of the fault plane. Figure 3(c) compares the synthetic waveforms computed for this model

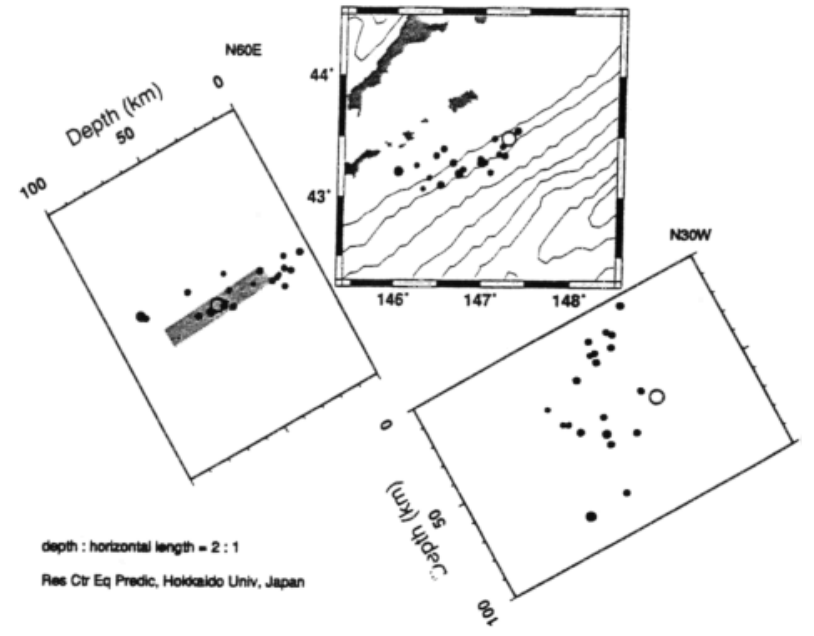

Figure 2. Spatial distribution of aftershocks within one day after the main shock which are determined by Hokkaido University. Open circles indicate the initial break of a main rupture determined in the present study. A shaded zone in the cross section perpendicular to $\mathrm{N}^{\circ} 60 \mathrm{~B}$ corresponds to one of two possible fault planes inferred from the mechanism solution.

with the observed ones. The waveform match is good at all stations with a normalized variance (residual error) of $30 \%$.

The main source parameters obtained are: location of the initial break $=\left(43.48^{\circ} \mathrm{N}, 147.40^{\circ} \mathrm{E}\right)$; centroid depth $=56 \mathrm{~km}$; average mechanism $\left(\phi_{s}, \delta, \lambda\right)=\left(49^{\circ}, 75^{\circ}, 125^{\circ}\right)$; total scalar moment $M o=2.6 \times 10^{21} \mathrm{Nm}\left(M_{w}=8.2\right)$; source time duration $T=42 \mathrm{~s} ;$ average rupture velocity $v=2.5 \mathrm{~km} / \mathrm{s}$.

Referring to the aftershock area shown in Figure 2, and the subevent distribution shown in Figure 3(b), we roughly estimate the fault area as $S=120 \times 60 \mathrm{~km}^{2}$. Then, using the shear modulus $\mu=64 \mathrm{GPa}$, we obtain: average dislocation, $D=M o / \mu S=5.6$ $\mathrm{m}$; average stress drop, $\Delta \sigma=2.5 \mathrm{Mo} / S^{1.5}=11 \mathrm{MPa}$.

We obtained $M_{o}=2.3 \times 10^{21} \mathrm{Nm}$ from the surface wave analysis mentioned above. We note here that the moment estimates reported for this event by different investigators are very different: for example, $M_{o}$ (in $10^{21} \mathrm{Nm}$ ) $=3.7$ (Harvard, surface
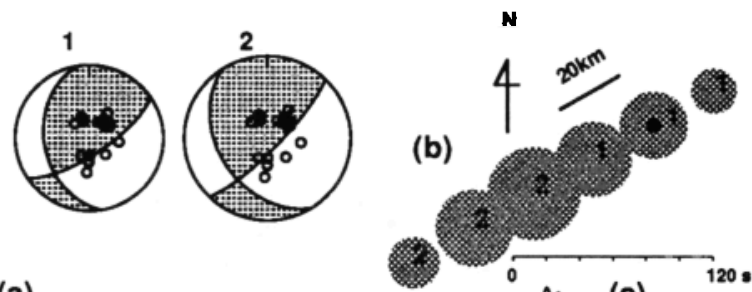

(a)
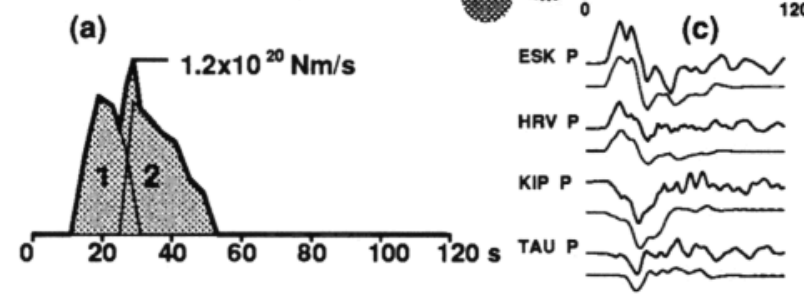

Figure 3. Results of body wave inversion. (a) Thin curves show the moment-rate for two individual mechanisms and the thick curve shows the total. (b) Epicentral distribution of subevents. Black circle denotes the initial break. The radius of gray circles is proportional to the moment. (c) Waveform comparison between the observed (upper) and the synthetic (lower) at several stations. The amplitudes of the observed and synthetic waveforms are plotted on a common scale with the actual amplitude ratio for each of the $P$ - and $S H$-components. 
waves), 1.5 (NEIS, body waves), 1.9 to 2.2 (surface waves, Y. Tanioka, personal communication, 1995), 1.1 (ERI, Univ. Tokyo, body waves), and 2.0 (surface waves, $H$. Thio, personal communication, 1995). This scatter may be partly due to the large vertical extent of the source. In surface-wave methods, excitation functions vary with depth significantly, and in bodywave methods, the geometrical spreading factor varies with depth. Thus the results may depend on how a finite fault extending over a large depth range is approximated by a point source. The centroid concept becomes somewhat ambiguous in this case.

\section{Crustal Deformation}

A GPS network installed in Hokkaido by the Geographical Survey Institute (GSI) of Japan began operations at the end of September, 1994, just one week before the earthquake. The results on the crustal deformation in Hokkaido were broadcast soon (two days) after the earthquake by GSI. In general all the bench marks in eastern Hokkaido moved eastward and subsided. For example, at Nemuro $\left(43.3^{\circ} \mathrm{N}, 145.6^{\circ} \mathrm{E}\right)$ the bench mark moved $42 \mathrm{~cm}$ east and subsided by $18 \mathrm{~cm}$ [Tsuji et al., 1994]. Also a tide gauge on Shikotan Is. recorded a coseismic subsidence of about $60 \mathrm{~cm}$ [Guseva et al., 1994].

We computed crustal deformation patterns using a half-space medium for the two possible fault models, steep fault and shallow-dip fault. We assumed a uniform dislocation of $5.6 \mathrm{~m}$ over the fault area of $120 \times 60 \mathrm{~km}^{2}$. For the steep-fault model, the northeast comer of the fault plane is placed at the location of initial break; for the shallow-dip fault model, the mid point of the upper edge of the fault plane is placed at the location of the initial break. The depth of the top of the fault was set at 20 km. As shown in Figure 4(a) (horizontal component) and 4(b) (vertical component), the displacements computed for both models agree well with the observed, but it is not possible to distinguish the two models. Eastern Hokkaido is too far from the source region to distinguish the displacement fields for the two models.

The subsidence of $60 \mathrm{~cm}$ at Malokurilskaya on Shikotan Is is the key for distinguishing the two models. Although both steep and shallow-dip models produce a similar crustal deformation pattern as shown in Figure $4(\mathrm{c})$ and $4(\mathrm{~d})$, the maximum subsidence for the shallow-dip model is $40 \mathrm{~cm}$, while it is 60 $\mathrm{cm}$ for the steep model. Thus only the steep model could explain an observed subsidence as large as $60 \mathrm{~cm}$ on Shikotan Is. However, since the exact location of the fault plane with respect to Shikotan Is., the depth of the upper edge of the fault, and the details of slip distribution are somewhat uncertain, we cannot completely rule out the shallow-dip model.

\section{Lithospheric Earthquake}

The results obtained from body wave inversion, aftershock distribution and the subsidence of Shikotan Is., taken together, suggest that the steep nodal plane is the fault plane. Since the main rupture occurred at depths of 40 to $60 \mathrm{~km}$, the rupture surface is entirely in the oceanic lithosphere. Hence we conclude that the 1994 Shikotan earthquake is a large intra-plate earthquake within the oceanic lithosphere. The very high stress drop, $11 \mathrm{MPa}$, is also diagnostic of intra-plate earthquakes [Kanamori and Anderson, 1975].

Thus the occurrence of this large earthquake only 25 years
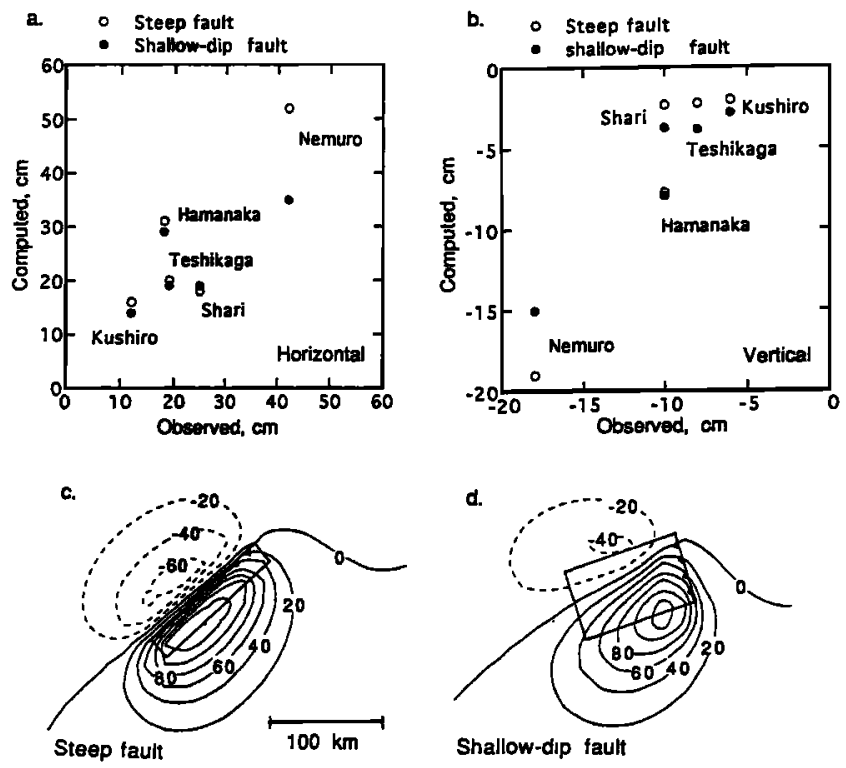

Figure 4. (a) Observed and computed horizontal displacements at several bench marks in eastern Hokkaido. All the displacements are almost eastward, and only the magnitudes are shown. (b) Observed and computed vertical displacements at several bench marks in eastern Hokkaido. (c) Vertical displacement in $\mathrm{cm}$ computed for the steep-fault model. (d) Vertical displacement in cm computed for the shallow-dip fault model.

after the 1969 Kurile Is. earthquake $\left(M_{s v}=8.2\right)$ in the same region is not surprising. The 1969 event has been studied by several investigators and interpreted as an inter-plate thrust earthquake [see Abe, 1973; Schwartz and Ruff, 1985; Kikuchi and Fukao, 1987].

\section{Discussion}

Large shallow intra-plate earthquakes are generally considered unusual, though recent studies show that this type of large intra-plate earthquake is relatively common. They include $M 8$-class events such as the 1933 Sanriku $\left(M_{w}=8.4\right)$ [Kanamori, 1971; Ben-Menachem, 1977] and the 1977 Sumba Sea $\left(M_{w}=8.2\right)$ [Spence, 1986; Kikuchi and Fukao, 1987; Lynnes and Lay, 1988]. Table 1 lists large intra-plate earthquakes with $M_{w} \geq 7.4$.

These earthquakes are often referred to as "lithospheric earthquakes" [Kanamori, 1971] since they are large enough to rupture through a substantial part of the oceanic lithosphere. Among these events, those that occur in the trench outer-rise region are called outer-rise earthquakes [e.g. Stauder, 1968; Christensen and Ruff, 1988; Zhang and Lay, 1992].

In the general framework of plate tectonics, lithospheric plates are considered rigid and not susceptible to brittle failure, and inter-plate motion is responsible for large earthquakes. While this is generally true, it is important to recognize that large $(M>8)$ earthquakes do occur relatively frequently within the oceanic lithosphere, resulting in significant deformation of the plates on subduction.

Large lithospheric earthquakes such as the 1994 Shikotan earthquake have an important implication for long-term assessment of seismic hazard in subduction zones. For example, the concept of seismic gap has been used to assess seismic potential in subduction zones [e.g. Fedotov, 1965; Mogi, 1969; Kelleher et al., 1973]. However, only inter-plate earthquakes on the plate boudary are considered in this application. Since 
Table 1 Shallow lithospheric events $\left(M_{w} 27.4\right)$ at subduction zones

\begin{tabular}{lcrcc}
\hline Earthquake & Date & Depth & $M_{w}$ & References \\
\hline Sanriku & $1933-03-02$ & $10 \mathrm{~km}$ & 8.4 & Kanamori [1971] \\
Shioya-Oki & $1938-11-06$ & 17 & 7.7 & $(1)$ \\
Chile & $1950-12-09$ & 100 & 7.9 & $(2)$ \\
Rat Is. & $1965-03-30$ & 20 & 7.5 & $(3)$ \\
Peru & $1970-05-31$ & 43 & 8.0 & $(4)$ \\
Tonga & $1975-10-11$ & $0-35$ & 7.4 & $(5)$ \\
Tonga & $1977-06-22$ & $40-70$ & 8.0 & $(5),(6)$ \\
Sumba & $1977-08-19$ & 33 & 8.2 & $(7),(8),(9)$ \\
Tonga & $1977-10-10$ & 20 & 7.4 & $(10)$ \\
Mariana & $1990-04-05$ & 23 & 7.5 & $(11)$ \\
Kushiro-Oki & $1993-01-15$ & 100 & 7.6 & $(12)$ \\
Shikotan & $1994-10-04$ & $25-85$ & 8.3 & This study \\
\hline
\end{tabular}

(1) Abe, K., Tectonophysics, 41, 269, 1977. (2) Kausel, E. and J. Campos, Phys. Earth Planet. Inter., 72, 220, 1992. (3) Abe, K., Phys. Earth Planet. Inter., 5, 190, 1972. (4) Abe, K., Phys. Earth Planet. Inter., 5, 367, 1972. (5) Christensen, D.H. and T. Lay, J. Geophys. Res., 93, 13367, 1988. (6) Lundgren, P.R. and E.A. Okal, J. Geophys. Res., 93, 13355, 1988. (7) Spence, W., J. Geophys. Res., 91, 7225, 1986. (8) Kikuchi, M. and Y. Fukao, Tectonophysics, 144, 231, 1987. (9) Lynnes, C.S. and T. Lay, J. Geophys. Res., 93, 13407, 1988. (10) Eissler, H. and H. Kanamori, Phys. Earth Planet. Inter., 29, 161, 1982. (11) Satake, K. et al., Geophys. Res. Lett., 19, 301, 1992. (12) Takeo, M. et al., Geophys. Res. Lett., 20, 2607, 1993.

large lithospheric earthquakes are relatively frequent as shown in Table 1, their occurrence would significantly increase the regional seismic potential estimated with the seismic gap method.

Compared with inter-plate earthquakes, lithospheric earthquakes, or more generally intra-plate earthquakes, in the same region are less frequent, but their location and repeat times are more unpredictable. Thus, if intra-plate earthquakes are included, long-term estimates of regional seismic potential would be inevitably far more uncertain than if only inter-plate earthquakes are considered. This inevitable uncertainty must be borne in mind in any strategy for earthquake hazard mitigation.

Acknowledgements. We thank Kei Katsumata and Hiromichi Tsuji for permitting us to use their results. We also thank Göran Ekstrom, Yuichiro Tanioka, Hitoshi Kawakatsu, and Hong-Kie Thio for letting us examine their moment determinations. This research was partially supported by the Grant-In-Aid for Scientific Research No.04452067 from the Ministry of Education, Japan, and by the National Science Foundation Grant EAR-9303804, USA. Contribution No. 5500, Division of Geological and Planetary Sciences, California Institute of Technology, Pasadena, California 91125.

\section{References}

Abe, K., Tsunami and mechanism of great earthquakes, Phys. Earth Planet. Inter., 7, 143-153, 1973.

Ben-Menahem, A., Renormalization of the magnitude scale, Phys. Earth Planet. Inter., 15, 315-340, 1977.

Christensen, D.H. and L.J. Ruff, Seismic coupling and outer rise earthquakes, $J$. Geophys. Res, 93, 13421-13444, 1988.
Fedotov, S.A., Regularities of the distribution of strong carthquakes in Kamchatka, the Kurile Islands, and northeastern Japan, Trudy Inst. Phys. Earth Acad. Sci. USSR, No.36, 66-93, 1965.

Fukao, Y. and M. Furumoto, Stress drops, wave spectra and recurrence intervals of great earthquakes - Implications of the Etorofu earthquake of 1958 November 6, Geophys. J. R. Astro. Soc., 57, 23-40, 1979.

Guseva, T.V. et al., The results of geological studies and global positioning system measurements over the Shikotan Island during Octover 1830, 1994, Russia Fed. Sys. Seism. Netw. Earthq. Pred., Spec. Iss., 22-30, 1994.

Kanamori, H., Seismological evidence for a lithospheric normal faultingthe Sanriku earthquake of 1933, Phys. Earth Planet. Inter., 4, 289300. 1971.

Kanamori, H., The energy release in great earthquakes, J. Geophys. Res., 82, 2981-2987, 1977.

Kanamori, H., and Anderson, D.L.. Theoretical basis of some empirical relations in seismology, Bull. Seism. Soc. Am., 65, 1073-1095, 1975.

Kanamori, H. and J.W. Given, Use of long-period surface waves for rapid determination of earthquake source parameters, Phys. Earth Planet. Inter., 27, 8-31, 1981.

Katsumata, K., M. Ichiyanagi and M. Kasahara, Aftershock distribution of the October 4, $1994 \mathrm{Mw} \mathrm{8.3} \mathrm{Kurile} \mathrm{Islands} \mathrm{earthquake} \mathrm{determined}$ by local seismic network in Hokkaido, Japan, submitted to Geophys. Res. Lett., 1995.

Kelleher, J., I. Sykes, and J. Oliver, Possible criteria for predicting earthquake locations and their application to major plate boundaries of the Pacific and the Caribbean, J. Geophys. Res., 78, 2547-2585, 1973.

Kikuchi, M. and Y. Fukao, Inversion of long-period P-waves from great earthquakes along subduction zones, Tectonophysics, 144, 231-247. 1987.

Kikuchi, M. and H. Kanamori, Inversion of complex body waves-III, Bull. Seism. Soc. Am., 81, 2335-2350, 1991.

Mogi, K., Some features of recent seismic activity in and near Japan (2), Activity before and after great earthquakes, Bull. Earthq. Res. Inst., 47, 395-417, 1969.

Schwartz, S.Y. and L.J. Ruff, The 1968 Tokachi-Oki and 1969 Kurile Islands earthquakes: variability in the rupture process, J. Geophys. Res., 90, 8613-8626, 1985.

Shimazaki, K., Correlation between intraplate seismicity and interplate earthquakes in Tohoku, northeast Japan, Bull. Seism. Soc. Am., 68, 181-192, 1978.

Stauder, W., Tensional character of earthquake foci beneath the Aleutian trench with relation to sea-floor spreading, J. Geophys. Res., 73, 7693-7701, 1968.

Tsuji, H., Y. Hatanaka, T. Sagiya, and M. Hashimoto, Coseismic crustal movements with October 4, 1994 Kurile Islands earthquake detected by a continuous GPS array in Japan, Program: S51F-06 in 1994 AGU Fall Meeting, 1994.

Utsu, T., Large earthquakes near Hokkaido and the expectancy of the occurrence of a large earthquake off Nemuro, Rep. Coord. Comm. Earthq. Prediction, 7, 7-13, 1972.

Zhang, J. and T. Lay, The April 5, 1990 Mariana Islands earthquake and subduction zone stresses, Phys. Earth Planet. Inter., 72, 99-121. 1992.

M. Kikuchi, Dept. Physics, Yokohama City University, Yokohama 236, Japan. (e-mail: kikuchi@yokohama-cu.ac.jp)

H. Kanamori, Seismological Laboratory, California Institute of Technology, Pasadena, CA 91125. (e-mail: hiroo@seismo.gps.caltech.edu)

(Received January 13, 1995; revised February 28, 1995; accepted February 28, 1995.) 